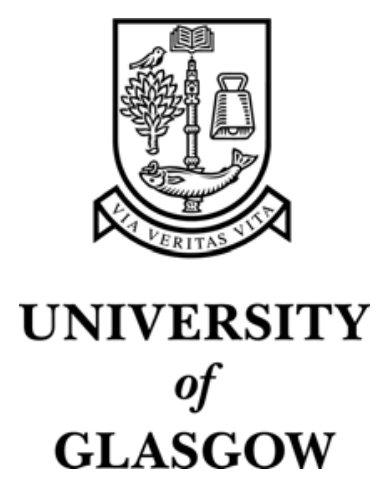

Sawata, T. and Kjaer, P.C. and Cossar, C. and Miller, T.J.E. and Hayashi, Y. (1999) Fault-tolerant operation of single-phase SR generators. IEEE Transactions on Industry Applications 35(4):pp. 774-781.

http://eprints.gla.ac.uk/archive/00002839/ 


\title{
Fault-Tolerant Operation of Single-Phase SR Generators
}

\author{
Tadashi Sawata, Associate Member, IEEE, Philip C. Kjaer, Member, IEEE, \\ Calum Cossar, T. J. E. Miller, Fellow, IEEE, and Yoichi Hayashi
}

\begin{abstract}
This paper studies fault-tolerant operation of multipole single-phase switched reluctance generators (SRG's), in particular, an 8/8-pole switched reluctance machine. The multipole single-phase SRG system is advantageous for reduced cost and higher efficiency compared to polyphase equivalents. However, using the classical phase-leg topology, a phase fault may prevent generating operation completely, since redundancy in the number of phases does not exist like polyphase systems. A new converter topology which connects two coil banks in parallel is proposed for higher fault tolerance with minimum additional cost. Faulty coils can be disconnected with the proposed converter and the SRG can continue generating operation after coil faults with reduced output power. Output power per coil current under faults is studied. Open- and short-circuit coils are studied through linear analysis, finite-element analysis, and static torque measurement. Generated currents under faults with the proposed converter are measured. The capability of the system to disconnect faulty coils dynamically is also shown.
\end{abstract}

Index Terms-Fault tolerant, single-phase multipole machine, split-winding converter, switched reluctance generator.

\section{INTRODUCTION}

$\mathbf{T}$ HE switched reluctance generator (SRG) currently receives an increasing amount of interest for aircraft power generation and applications where robustness, high speed, and fault tolerance are of major importance [1]-[5]. The classic converter topology (asymmetrical H-bridge) [6] with the motor phase winding placed between the power electronic semiconductors avoids the problem of shoot-through faults found in ac inverter technology. Furthermore, the short-pitched windings exhibit a large amount of electromagnetic independence, which may be exploited by appropriate converter, as well as machine, topologies.

Paper IPCSD 98-86, presented at the 1997 IEEE Applied Power Electronics Conference and Exposition, Atlanta, GA, February 23-27, and approved for publication in the IEEE TRANSACTIONS ON INDUSTRY APPLICATIONS by the Electric Machines Committee of the IEEE Industry Applications Society. The work of T. Sawata was supported by NSK Ltd., Tokyo, Japan. Manuscript released for publication December 14, 1998.

T. Sawata was with the SPEED Laboratory, Department of Electronics and Electrical Engineering, University of Glasgow, Glasgow, G12 8LT, U.K. He is now with the Mechatronics Products Engineering Department, NSK Ltd., Gunma 371-8527, Japan (e-mail: TadashiSaeko@msn.com).

P. C. Kjaer is with the Department of Power Engineering, ABB Corporate Research, 72178 Vasteras, Sweden (e-mail: philip.kjaer@secrc.abb.se).

C. Cossar and T. J. E. Miller are with the SPEED Laboratory, Department of Electronics and Electrical Engineering, University of Glasgow, Glasgow, G12 8LT, U.K. (e-mail: c.cossar@elec.gla.ac.uk; T.Miller@elec.gla.ac.uk).

Y. Hayashi is with the Department of Electronics and Electrical Engineering, Aoyama Gakuin University, Tokyo 157-8572, Japan (e-mail: yoichi@ee.aoyama.ac.jp).

Publisher Item Identifier S 0093-9994(99)04398-4.
Much interest has been paid to the possibility of replacing the $400-\mathrm{Hz}$ ac power distribution found on many aircraft with a dc system at $270 \mathrm{~V}$. The switched reluctance (SR) machine has been identified as a potential candidate for the generator in such systems [3].

Relatively little has been reported on SR machines operating under fault conditions. It was suggested in [7] that SR motors could operate by disconnecting faulty windings with the use of special fault detectors. Refernece [8] reported an analysis of operation under faults and compared several winding configurations. SRG converter topologies for improved fault-tolerance have been studied in [4]. In [3], a dual-converter topology which has separate excitation and load buses was suggested, and the design of the power stage for SRG's was studied in [2]. Various methods for closed-loop control of the dc-link voltage were described in [9]-[11], and a reduction of the reactive power flow by on-line optimization was attempted in [12].

Most publications on the SR machine are on polyphase machines, and only limited numbers are on single-phase machines [13]-[16], a summary of the advantages of singlephase machines being as follows:

- fewer connections between motor and converter;

- fewer switching devices;

- higher inductance ratio between the aligned and unaligned positions.

The relative lack of interest shown in single-phase motors can, in part, be attributed to the fact that some starting assistant may be required because of the existence of torque dead zones. The torque dead zone may also lead to discontinuous torque, possibly producing large ripples. Furthermore, the properties of single-phase machines with equal numbers of stator and rotor poles appear to have been largely overlooked-even for generators, where self-starting is not required. It is probable that an excessive preoccupation with torque ripple has discouraged the development of these machines, even though torque ripple is not a serious issue in many applications. Hayashi and Miller studied and built a multipole single-phase SR machine for a solar-powered vehicle application. They demonstrated the multipole single-phase SR machine can achieve higher efficiency over polyphase machines with identical stator outer diameter, stack length, and air-gap length [17].

In this paper, the fault-tolerant operation of a multipole single-phase SRG is studied, in particular, an 8/8-pole machine. The following topics are described:

- how to employ a multipole single-phase SR machine for maximum fault tolerance; 


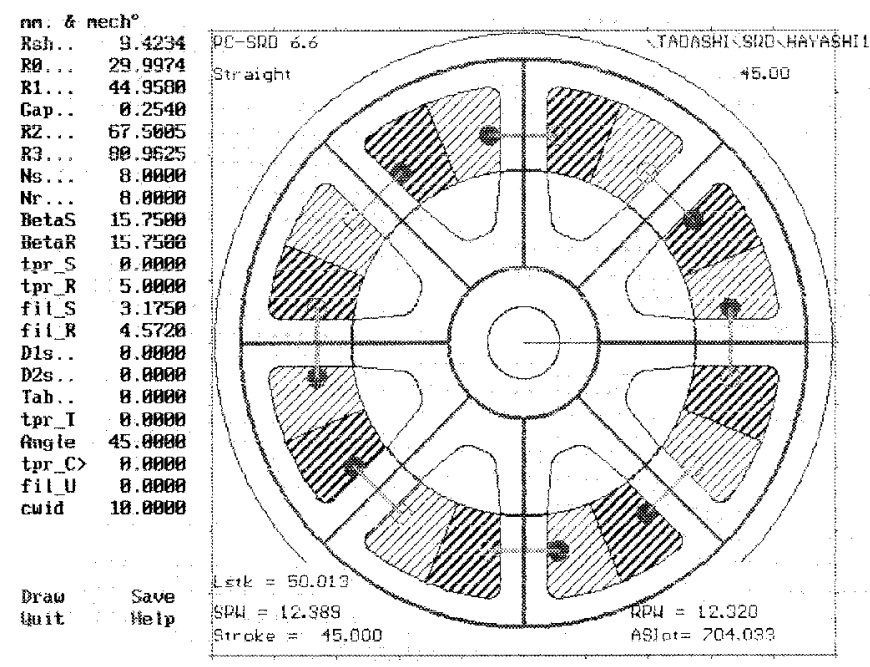

Fig. 1. Cross section of the prototype 8/8-pole single-phase SR machine.

- expected performance under faults;

- winding configurations for minimized impact from faults;

- capability of the split-winding converter to isolate faulty coils.

\section{Multipole Single-Phase SRG}

The cross section of a prototype single-phase SR machine with eight stator poles and eight rotor poles is shown in Fig. 1. The machine is wound with one coil per pole and the number of turns per pole $N_{p}$ is 35 . The design and construction of this machine is reported in [17]. The eight coils were initially connected such that adjacent poles have opposite magnetic polarity, producing so-called short flux paths. This has been reported to result in lower iron losses [18], which is of importance, in particular, in high-speed applications. The $8 / 8$ machine has narrower stator pole arcs than the equivalent $8 / 6$ machine, hence, a wider slot area is available, resulting in lower copper losses. On the other hand, a narrower pole arc may also reduce the aligned inductance and increase the pole flux density. For a more detailed discussion on the choice of pole numbers, see [19]. Apart from a high efficiency, the 8/8 machine appears attractive as its coils may be connected to minimize the impact of faults. In the following sections, several winding configurations are studied.

\section{PROPOSED SYSTEM}

Under normal conditions, all the poles are excited simultaneously in the single-phase SR machine and flux distribution is symmetrical, as shown in Fig. 5(a). However, the symmetry may not be sustained when a coil fault occurs. Fig. 2 shows such an example. It shows the flux distribution when one of eight coils is unexcited. Under this condition, unbalanced lateral forces will be produced [8], and this may lead to mechanical failure.

In polyphase SR systems, a faulty phase can be shut off and remaining phases could continue operation with reduced power. This will not cause unbalanced lateral forces, as each

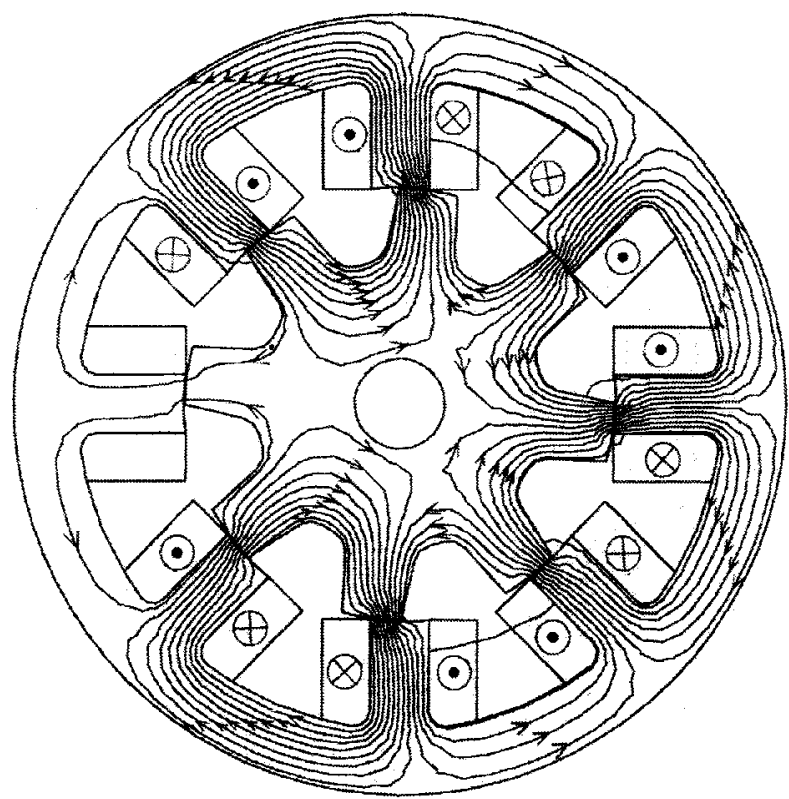

Fig. 2. Flux plots when one of eight coils is unexcited.

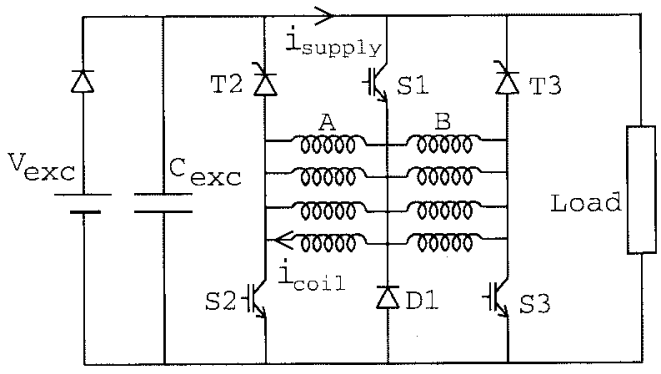

Fig. 3. Fault-tolerant single-bus converter circuit for split-winding single-phase SRG.

phase consists of two diametrically opposite poles and mutual coupling between phases is normally negligible.

For the single-phase system to tolerate a coil fault, the coils must be connected in parallel (two parallel banks of four coils in parallel or alike, with an increase in converter complexity). The split-winding converter shown in Fig. 3 is proposed. One of the two banks of coils can be disconnected from the power source when a fault in coils occurs with this converter. Under normal conditions $T 2$ and $T 3$ are always on, and $S 1, S 2$, and $S 3$ receive identical switching signals. In order to disconnect coil bank $B, S 3$ and $T 3$ are switched off and the generator is operated by controlling $S 1$ and $S 2$, with $T 2$ remaining on. With the proposed system, the magnetic balance can be maintained and the problem of lateral forces can be avoided by disconnecting a coil bank when one of the coils is faulty.

Other single-phase SRG topologies can be connected in a similar fashion, but the converter in Fig. 3 has the drawback of disconnecting half the total number of coils, even if just one coil is faulty. To separate a smaller number of coils, increased circuit complexity is required. Fig. 4 shows one such example.

There are several ways to configure the magnetic polarity of the coils with the converter in Fig. 3. For normal operation, the 8/8 SR machine should have four pairs of $N$ and $S$ coils. For a 


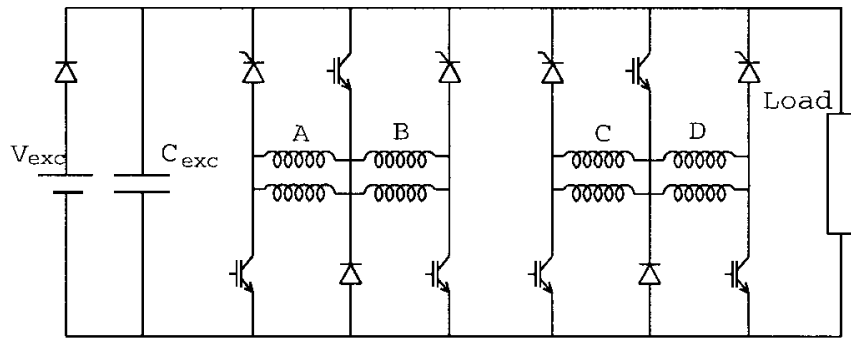

Fig. 4. Fault-tolerant single-bus converter circuit for split winding with four banks for the single-phase SRG.

TABLE I

DeFINITION OF OPEN-CoIl FaUlts

\begin{tabular}{l|l|l}
\hline \hline Case I & $\begin{array}{l}\text { Normal condition } \\
\text { Case II }\end{array}$ & 4-coil oper \\
Case III & 4 -coil open & (NONOSOSO) \\
Case IV & 4 -coil open & (NOSONOSO) \\
Case V & 1-coil open & \\
\hline \hline O refers to an open-circuit coil &
\end{tabular}

fault operation in which half the coils are disconnected (open circuited), the polarity of remaining coils could be either two pairs of $N$ and $S$ or four of either polarity from a symmetrical point of view. Here, the five cases in Table I are examined. The study of a one-coil open-circuit fault is a good example to show how the magnetic unbalance affects the operation. The one-coil short-circuit fault is also discussed in later sections, although it is not listed here.

Fig. 5 shows the flux paths of the machine for Cases I-IV when the remaining coils are excited by a coil current of $10 \mathrm{~A}$, which is half the rated coil current of $20 \mathrm{~A}$, calculated using finite-element analysis (FEA). Fig. 5(a) shows the short flux paths of Case I corresponding to the rated phase current of 80 A with the converter of Fig. 3. For Cases II and III, the flux in open-circuit coil poles is cancelled by the MMF of the conducting coils under linear conditions. For Case IV, the flux paths remain unchanged from Case I, although the flux density decreases with decreased MMF level.

\section{FAULT ANALYSIS}

In this section, the performance of the single-phase SR machine under faults (after half the coils are disconnected) is calculated by linear analysis. The equivalent magnetic circuit of the machine is shown in Fig. 6. The MMF potential is defined 0 at the stator yoke and $F_{0}$ at the rotor yoke. $F_{k}$ represents the MMF of coil " $k$," $R_{k}$, represents the air-gap reluctance, and $\phi_{k}$ represents the flux through the pole. $F_{0}$ and $\phi_{k}$ are expressed by the following equations:

$$
\begin{aligned}
F_{0}=\frac{\sum_{k} \frac{F_{k}}{R_{k}}}{\sum_{k} \frac{1}{R_{k}}} \\
\phi_{k}=\frac{F_{k}-F_{0}}{R_{k}} .
\end{aligned}
$$

Since all air-gap reluctances are the same for the singlephase machine, it follows that

$$
F_{0}=\frac{\sum_{k} F_{k}}{8}
$$

For a simple comparison between normal and faulted conditions, a normalized permeance profile, shown in Fig. 7, is assumed. Using this permeance profile, torque produced on each pole $T_{k}$ is expressed as follows:

$$
T_{k}=\frac{1}{2}\left(F_{k}-F_{0}\right)^{2} \frac{d P}{d \theta}=\frac{1}{2}\left(F_{k}-F_{0}\right)^{2} .
$$

\section{A. Case I}

The MMF in each pole is such that

$$
\begin{aligned}
& F_{1}=F_{3}=F_{\tilde{5}}=F_{7}=N_{p} i \\
& F_{2}=F_{4}=F_{6}=F_{8}=-F_{1}
\end{aligned}
$$

where $N_{p}$ is the number of turns per pole. This gives total torque $T_{\mathrm{I}}$ for Case I

$$
T_{\mathrm{I}}=8 T_{k}=4 N_{p}^{2} i^{2} .
$$

This torque will be compared with the torque produced during faults.

\section{B. Cases II and III}

Cases II and III give the same result with linear analysis. The configuration of the MMF is as follows:

$$
\begin{aligned}
& F_{1}=F_{5}=-F_{3}=-F_{7}=N_{p} i \\
& F_{2}=F_{4}=F_{6}=F_{8}=0 .
\end{aligned}
$$

The total torque $T_{\text {II,III }}$ for Cases II and III is

$$
T_{\mathrm{II}, \mathrm{III}}=2 N_{p}^{2} i^{2}=0.5 T_{\mathrm{I}} \text {. }
$$

\section{Case IV}

The MMF in each pole is such that

$$
\begin{aligned}
& F_{1}=F_{3}=F_{5}=F_{7}=N_{p} i \\
& F_{2}=F_{4}=F_{6}=F_{8}=0 .
\end{aligned}
$$

The total torque $T_{\mathrm{IV}}$ for Case IV is

$$
T_{\mathrm{IV}}=N_{p}^{2} i^{2}=0.25 T_{\mathrm{I}}
$$

\section{Case V}

The MMF of each coil is as follows:

$$
\begin{aligned}
& F_{1}=F_{3}=F_{5}=F_{7}=N_{p} i \\
& F_{4}=F_{6}=F_{8}=-N_{p} i \\
& F_{2}=0 .
\end{aligned}
$$

Then, the total torque $T_{\mathrm{V}}$ for Case $\mathrm{V}$ is

$$
T_{\mathrm{V}} \approx 3.44 N_{p}^{2} i^{2}=0.86 T_{\mathrm{I}} .
$$

Table II summarizes the analysis. It shows that the singlephase SRG could generate half the normal power when four of eight coils are conducting, with the winding configuration of either Case II or III. 


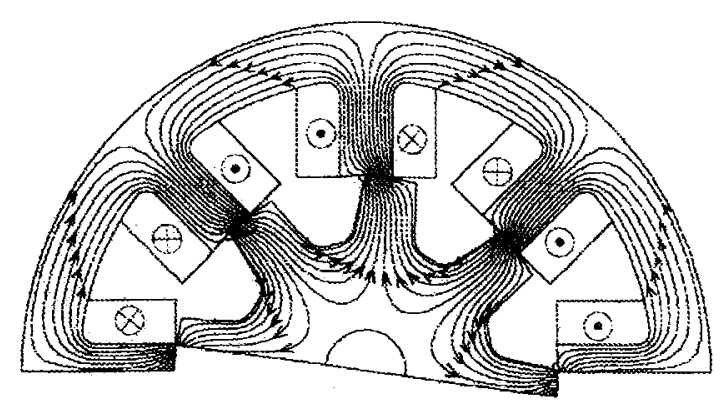

(a)

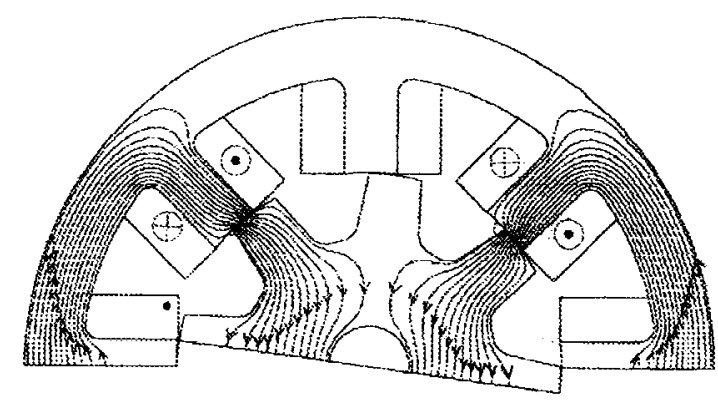

(b)

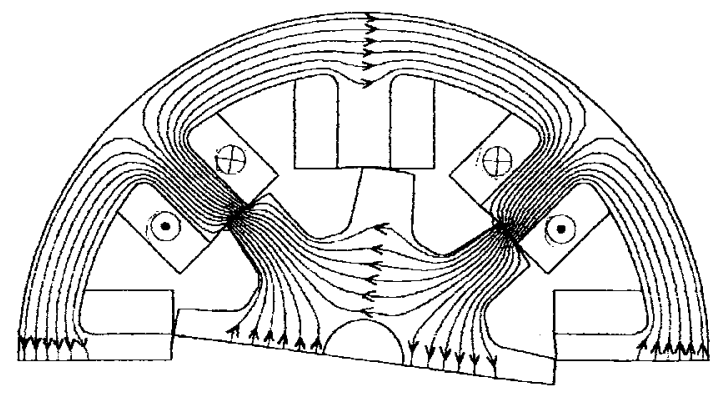

(c)

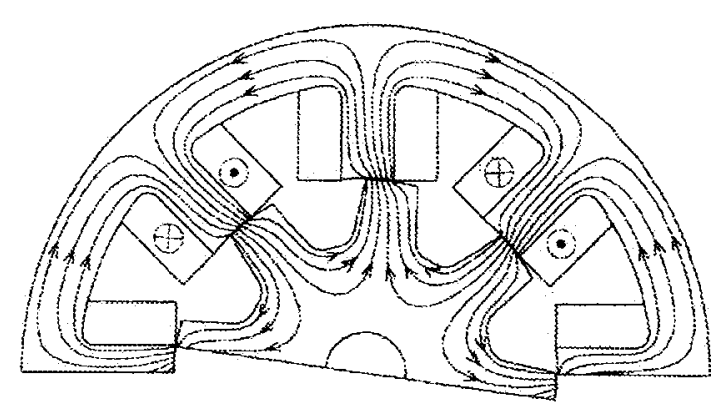

(d)

Fig. 5. Flux plots calculated using FEA. (a) Case I. (b) Case II. (c) Case III. (d) Case IV.

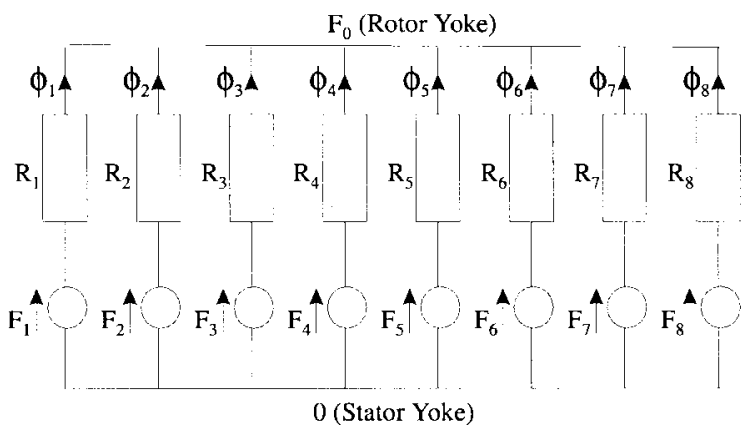

Fig. 6. Equivalent magnetic circuit of the single-phase SR machine.

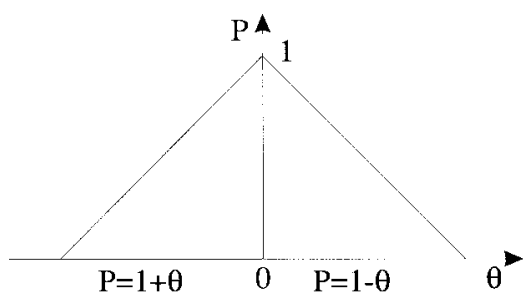

Fig. 7. Normalized permeance profile.

TABLE II

Torque Production Analysis Under Open-CoIl Faults

\begin{tabular}{l|l}
\hline \hline Faults & Iorque (vs. Case I) \\
\hline Case II, III & $50 \%$ \\
Case IV & $25 \%$ \\
Case V & $86 \%$ \\
\hline \hline
\end{tabular}

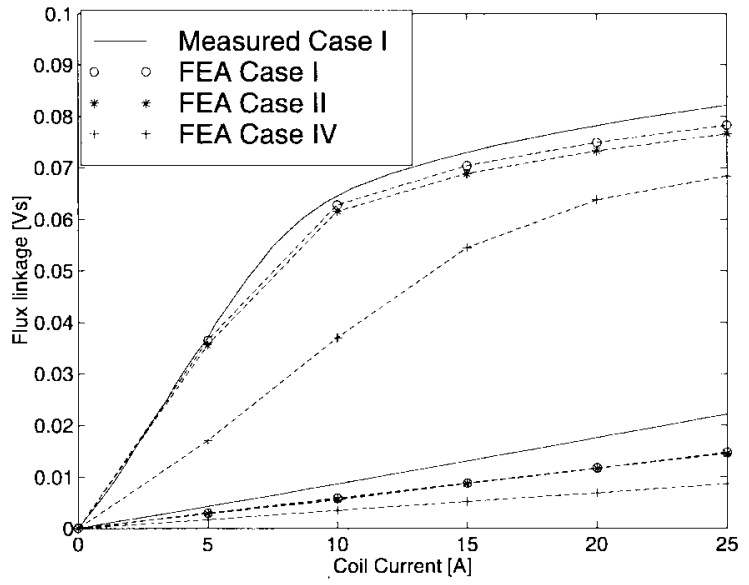

Fig. 8. Magnetization curves under normal operation and open circuit of four coils.

\section{TWO-DiMENSIONAL FEA AND STATIC TORQUE MEASUREMENT}

In this section, the previous analysis is confirmed through comparison with FEA and static torque measurement.

Fig. 8 shows the magnetization curves for the experimental machine for two rotor positions (maximum and minimum inductance). Measurements with all eight coils connected and FEA predictions for Cases I, II, and IV are shown, all for identical coil current levels. The magnetization curves of Case III may be expected to be similar to those of Case II. The flux linkage for Case II is at the same level as that of Case I and, for Case IV, half that of Case I, with the same coil current. 


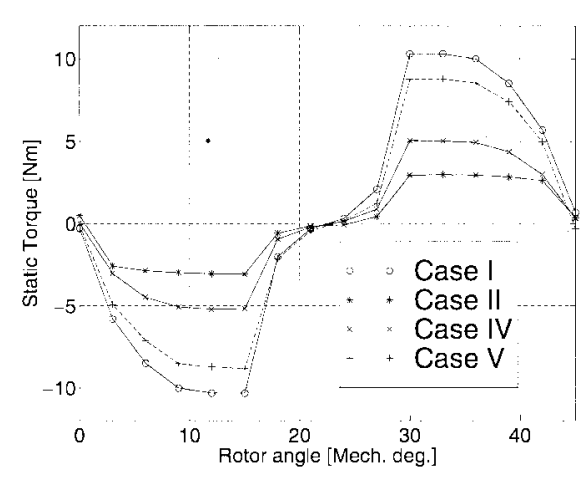

Fig. 9. Measured static torque curves.

With the connection shown in Fig. 3, the supply current for Cases II and IV is half that of Case I. Assuming that energy converted is proportional to the area bounded by $\max / \mathrm{min}$ inductance lines at rated current, Fig. 8 gives the same output torque prediction as in Table II.

A series of static torque curves of the prototype single-phase SRG was measured up to a coil current of 15 A (maximum coil current was limited by dc power supply available in the laboratory). Here, curves for a coil current of 15 A only are shown for clarity in Fig. 9. The static torque of the machine for Case II is $50 \%$ of Case I. The same measurement was carried out for Case III and it gave the same result as Case II, although this is not shown in Fig. 9. The static torque for Case IV is $25 \%$ of that of Case I. When one of the eight coils is open circuited (Case V), the static torque is $86 \%$ of Case I. When the coils are split into two banks, the magnetic polarity of Case II should be configured. The measurement results support the analytical predictions well.

The result confirms that the available power per coil current during faults is

$$
P_{\text {fault }}=P_{\text {normal }} \frac{N-n}{N}
$$

where $N$ is the number of coils and $n$ the number of faulted coils. The single-phase SRG could generate half its normal energy when half the coils are disconnected and currents in the remaining coils are normal.

\section{Generating Test}

Steady-state generating tests were performed and the load currents measured. The measurement system is shown in Fig. 10. The SRG was turned by a motor at a constant speed. An external supply $V_{\text {ext }}$ was used to charge the capacitor banks initially and used as backup if the voltage could not be sustained. The SRG is inherently unstable when operated with the single-pulse excitation and requires the firing angles to be adjusted to match the load exactly [3]. In the test, for a set of firing angles, the load was adjusted manually to assure equilibrium (constant $V_{o}$ ) and the load current $I_{o}$ was measured $\left(V_{o}\right.$ increases or decreases exponentially without the equilibrium.). The same procedure was applied for normal operation, as well as short- and open-circuit tests. Generated power was limited to the lower part of the system rating

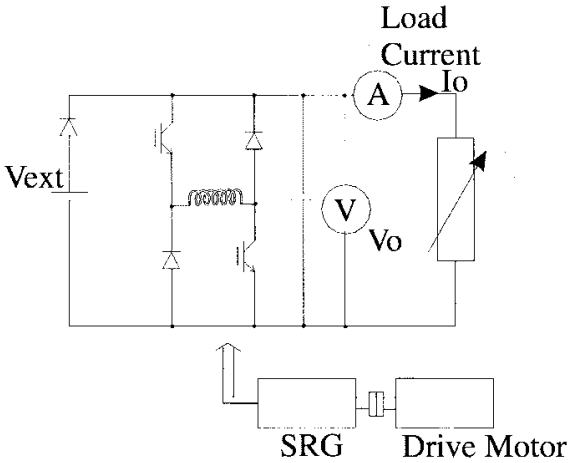

Fig. 10. Experimental SRG setup.

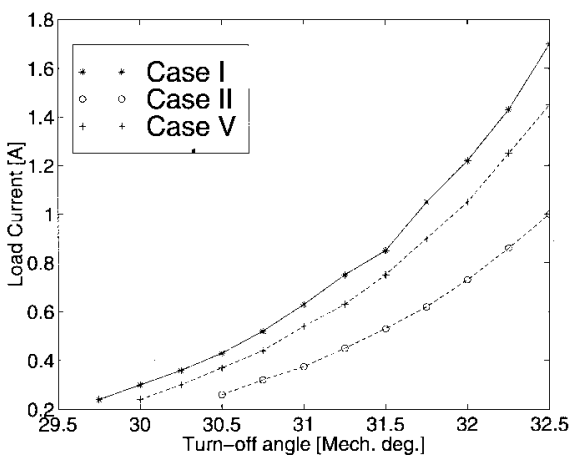

Fig. 11. Load current under normal and open-coil fault conditions (1500 $\left.\mathrm{r} / \mathrm{min}, V_{o}=30 \mathrm{~V}\right)$.

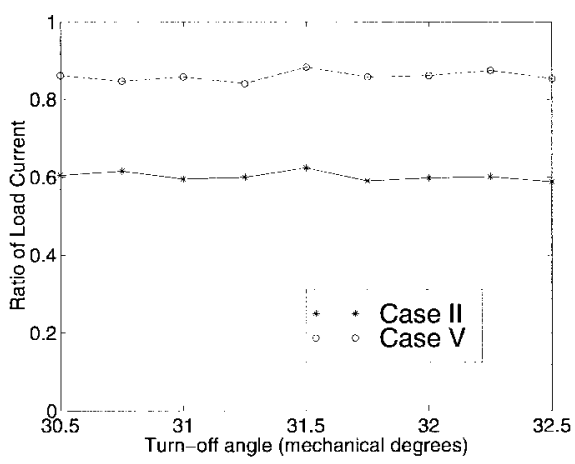

Fig. 12. Ratio of load current under open-coil faults (load current for case $\mathrm{I}=1)$.

and could not be increased for safety reasons, because of the unstable nature of the SRG system.

\section{A. Operation With Half the Coils Disconnected}

The generated currents were measured for the winding configurations of Cases I, II, and V. Fig. 11 shows the load current measured at $1500 \mathrm{r} / \mathrm{min}$ with $V_{o}=30 \mathrm{~V}$, and a fixed turn-on angle of 20.8 mechanical degrees relative to the unaligned position. Fig. 12 shows the load current of Cases II and V normalized with Case I. For Case II, the load current is approximately $60 \%$ of that under normal condition at the same switching angles. This is approximately 10\% larger than the analytical result. This may be because constant currents are 
TABLE III

Definition of Short-Circuit CoIl Faults

\begin{tabular}{l|l|l}
\hline \hline Case I & Normal condition & (NSNSNSNS) \\
Case II' & 4-coil short & (N@N@S@S@) \\
Case III' & 4-coil short & (N@S@N@S@) \\
Case IV' & 4-coil short & (N@N@N@N@) \\
\hline \hline
\end{tabular}

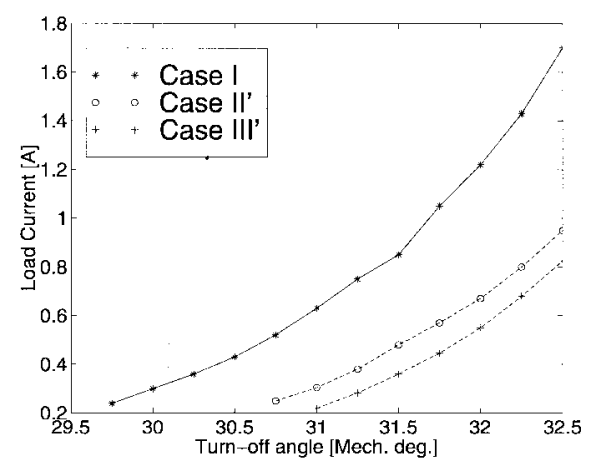

Fig. 13. Load current under normal and short-circuited coil fault conditions $\left(1500 \mathrm{r} / \mathrm{min}, V_{o}=30 \mathrm{~V}\right)$.

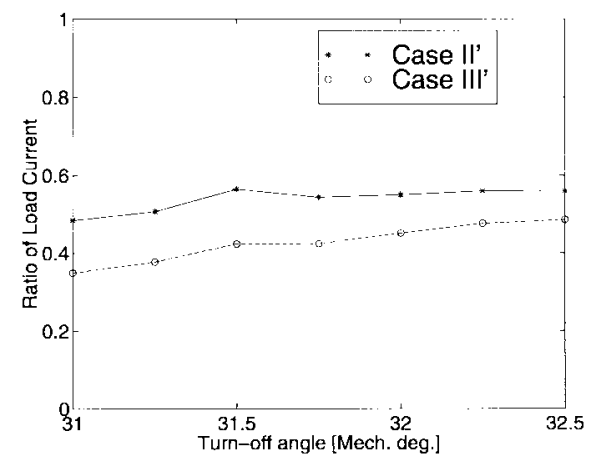

Fig. 14. Ratio of generated current under short-circuited coil faults (generated current for case $I=1$ ).

assumed in the linear analysis. In practice, the current levels for Cases I and II may differ as a result of the single-pulse control and the difference in impedance on opening four coils. For Case V, the load current is approximately $86 \%$, which agrees with the analytical prediction.

\section{B. Short-Circuit Coil Faults}

The generating tests were also carried out with some of the coils short circuited, instead of open circuited (disconnected). The fault conditions are listed in Table III.

Fig. 13 shows the load current measured for the same conditions as for the open-circuit faults. Fig. 14 shows the ratio of the load current. For Cases II' and III', the load current is around $10 \%$ smaller than the open-circuit faults. Induced current in the short-circuit coils may reduce the output of the SRG. The induced current was observed and its amplitude was around $10 \%$ of that of the healthy current. Case II' generates slightly larger energy than Case III' does. The flux paths of Case II' may reduce the amount of flux which goes through the short-circuited coils. For Case IV', no output was
TABLE IV

PERformance Under Faults

\begin{tabular}{l|l}
\hline \hline Coil open-circuit faults & Outpnt (vs. normal) \\
\hline Case II & $50 \%$ \\
Case III & $50 \%$ \\
Case IV & $25 \%$ \\
Case V & $86 \%$ \\
\hline Coil short-circuit faults & \\
\hline Case II' & $50 \%$ \\
Case III' & $40 \%$ \\
Case IV & $0 \%$ \\
\hline
\end{tabular}

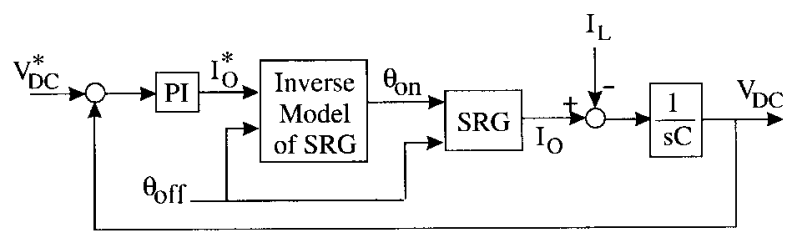

Fig. 15. DC-bus voltage controller.

measured and a very large current flowed from the external power supply. Short circuit of coils for this configuration is equivalent to a transformer, the secondary coil of which is short circuited because the same amount of flux goes through the short-circuited coils as healthy coils.

The analyses and experimental results are summarized in Table IV. It may be concluded that, for management of faults in coils with the converter in Fig. 3, the winding configuration of Case II has the highest fault tolerance.

\section{DYNAMIC OPERATION OF DisCONNECTING FAULTY BANK}

This section demonstrates the capability of the proposed system to disconnect a faulty bank dynamically by experiments. A detailed analysis on the transient states is presented in [20].

\section{A. DC-Bus Voltage Controller}

In the experiments, a linearized controller which is based on an inverse model of the SRG was used to control the dc-bus voltage [11]. Fig. 15 shows the block diagram of the controller. The dc-bus voltage $V_{\mathrm{DC}}$ is compared with its reference value and the difference is input to the proportional integral (PI) controller. The PI controller outputs the reference value of the net generating current $I_{O}^{*}$. The inverse model of the SRG is used to calculate the switching angles from $I_{O}^{*}$ at the given $V_{\mathrm{DC}}$ and speed. In this experiment, the turn-off angle $\theta_{\text {off }}$ was kept constant, but could also be varied to optimize some secondary goal.

\section{B. Experimental Results}

Fig. 16 shows current waveforms when one of the $S$ coils in coil bank $B$ is open circuited and the faulty bank $B$ is disconnected by turning off the semiconductor switches which correspond to bank $B$. Before disconnection, the balance between $N$ and $S$ coils does not exist and the currents in $S$ coils $I_{S A}$ and $I_{S B}$ are forced to be small by the mutual coupling between the coils. Circulating currents through parallel-connected coils are also induced, which will increase 


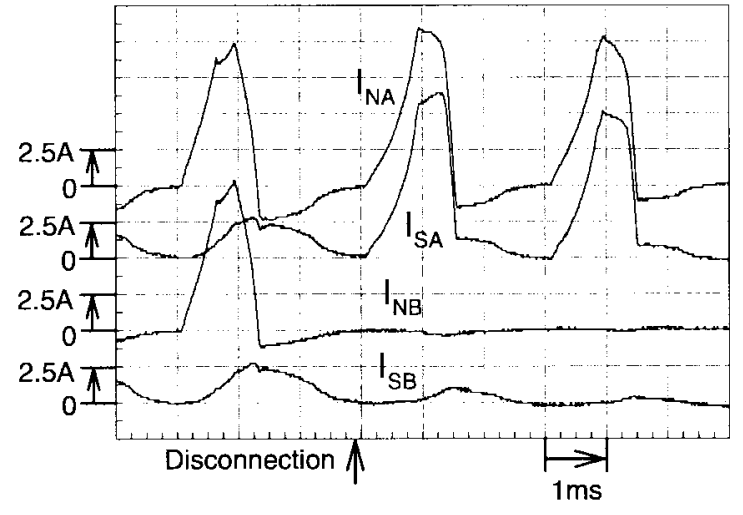

Fig. 16. Current waveforms when disconnecting the faulty bank. (Subscripts $N$ and $S$ represent magnetic polarity of poles, and subscripts $A$ and $B$ represent coil banks $A$ and $B$.).

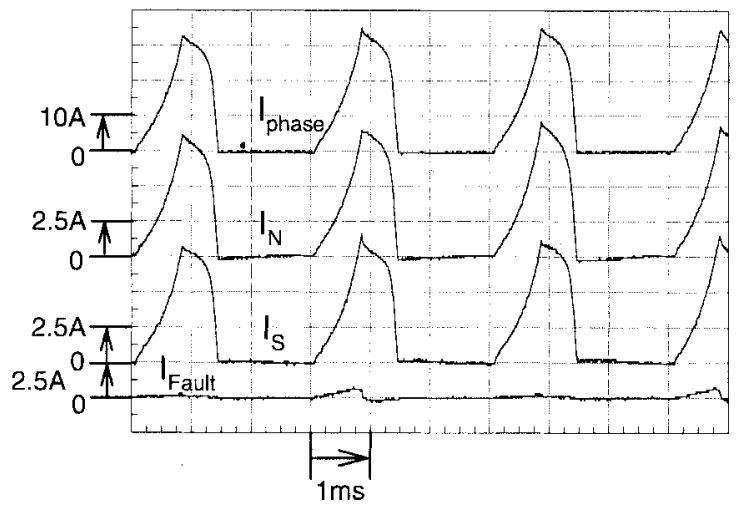

Fig. 17. One-coil short-circuit fault.

copper and iron losses. After disconnection, the currents in the disconnected coils $I_{N B}$ and $I_{S B}$ decrease with time, while the current in $S$ coils in the healthy bank $I_{S A}$ recovers and becomes the same level as that in the $N$ coils $I_{N A}$. The circulating currents in the healthy bank decrease, although these do not become zero. The reason why small circulating currents remain may be that a perfect balance in the healthy coils is not obtained because of the leakage inductance and the partial saturation of the steel in the prototype machine.

Fig. 17 shows the current waveforms when one coil is short circuited by a fault and the faulty bank is disconnected by turning off the corresponding semiconductor switches. The current in the short-circuited coil is very small, since the magnetic coupling between the banks is very small when one bank is turned off.

These results show that the proposed converter can disconnect a faulty bank with open- or short-circuit coil dynamically. Proper fault detectors must be employed, however, this topic is outside the scope of this paper. Detailed discussion on the fault detectors for SR machines is seen in [21].

\section{CONCLUSION}

This paper has demonstrated how to employ a multipole single-phase SR machine as a generator for higher fault tolerance with minimum increase in cost, in particular, the 8/8-pole single-phase machine. It has studied the operation with the split-winding converter under open- and short-circuit coil faults.

The linear analysis and FEA reveals that, with four of eight coils open, the SRG is still capable of generating half its normal power for the same coil current. This was confirmed by static torque measurement and generating tests. It is concluded that the winding configuration which gives NNSSNNSS magnetic polarity may be the best when the windings of the single-phase SRG are split into two banks in parallel. The capability to disconnect faulted coils with the proposed system has also been demonstrated by experiment.

Similar configurations can be applicable to multipole singlephase SR machines with different numbers of poles, i.e, a two-coil bank may be employed for a $4 / 4$ machine, a threecoil-bank may be the best for a $6 / 6$ machine, and so on. The multipole single-phase SR machine should be regarded as a serious candidate for generator applications, because a faulttolerant high-efficiency system can be achieved with lower cost.

\section{ACKNOWLEDGMENT}

The authors would like to thank J. R. Hendershot (formerly of Magna Physics Tridelta) and Magna Physics Tridelta, Mentor, $\mathrm{OH}$, for building the single-phase SRG. We also would like to thank J. Kelly, I. Young, P. Miller, and L. Kelly for building the experimental setup.

\section{REFERENCES}

[1] C. A. Ferreira, S. R. Jones, W. S. Heglund, and W. D. Jones, "Detailed design of a $30-\mathrm{kW}$ switched reluctance starter/generator system for a gas turbine engine application," IEEE Trans. Ind. Applicat., vol. 31, pp. 553-561, May/June 1995.

[2] S. R. MacMinn and W. D. Jones, "A very high speed switched reluctance starter-generator for aircraft engine applications," in Proc. NAECON'89, May 1989, pp. $1758-1764$.

[3] A. V. Radun, "Generating with the switched reluctance motor," in Proc. IEEE APEC'94, 1994, pp. 41-46.

[4] E. Richter and C. Ferreira, "Performance evaluation of a $250 \mathrm{~kW}$ switched reluctance starter generator," in Conf. Rec. IEEE-IAS Annu. Meeting, 1995, pp. 434-440.

[5] E. Richter, "High temperature, lightweight, switched reluctance motors and generators for future aircraft engine applications," in Proc. American Control Conf., 1988, pp. 1846-1851.

[6] T. J. E. Miller, Switched Reluctance Motors and Their Control. London, U.K.: Oxford Univ. Press, 1993.

[7] C. M. Stephens, "Fault detection and management system for faulttolerant switched reluctance motor drives," IEEE Trans. Ind. Applicat., vol. 27, pp. 1098-1102, Nov/Dec. 1991.

[8] T. J. E. Miller, "Faults and unbalance forces in the switched reluctance machine," IEEE Trans. Ind. Applicat., vol. 31, pp. 319-328, Mar./Apr. 1995.

[9] D. E. Cameron and J. H. Lang, "The control of high-speed variablereluctance generators in electric power systems," IEEE Trans. Ind. Applicat., vol. 29, pp. 1106-1109, Nov./Dec. 1993.

[10] A. V. Radun, "Linearizer for a switched reluctance generator," U.S. Patent 5204 604, Apr. 20, 1993.

[11] P. C. Kjaer, C. Cossar, J. J. Gribble, Y. Li, and T. J. E. Miller, "Switched reluctance generator control using an inverse machine model," in Proc. ICEM'94, 1994, pp. 380-385.

[12] P. C. Kjaer, C. Cossar, J. J. Gribble, T. J. E. Miller, and Y. Li, "Minimization of reactive power flow in switched reluctance generators," in Conf. Rec. IPEC-Yokohama'95, 1995, pp. 1022-1026.

[13] S. A. Nasar, "D.C.-switched reluctance motor," Proc. Inst. Elect. Eng., vol. 116, no. 6, pp. 1048-1049, June 1969. 
[14] H. R. Bolton and D. A. G. Pedder, "Low-cost reluctance drive system for low power, low speed application," in Proc. IEE Conf., 1979, Pub. 179, pp. 88-92.

[15] C. C. Chan, "Single-phase switched reluctance motors," Proc. Inst. Elect. Eng., vol. 134, pt. B, no. 1, pp. 53-56, Jan. 1987.

[16] J. C. Compter, "Microprocessor-controlled single-phase reluctance motor," in Proc. Drives/Motors/Controls Conf., Oct. 1984, pp. 64-68.

[17] Y. Hayashi and T. J. E. Miller, "Single-phase multi-pole SRM for solar-powered vehicle," in Conf. Rec. IPEC-Yokohama'95, 1995, pp. 575-579.

[18] A. Michaelides and C. Pollock, "Short flux paths optimize the efficiency of a 5-phase switched reluctance drive," in Conf. Rec. IEEE-IAS Annu. Meeting, 1995, pp. 286-293.

[19] H. C. Lovatt and J. M. Stephenson, "Influence of number of poles per phase in switched reluctance motors," Proc. Inst. Elect. Eng., vol. 139, pt. B, no. 4, pp. 307-314, July 1992.

[20] T. Sawata, P. C. Kjaer, C. Cossar, and T. J. E. Miller, "A study on the operation under faults with the single-phase switched reluctance generators," in Proc. IEEE APEC'98, Feb. 1998, vol. 2, pp. 1040-1046

[21] C. M. Stephens, "Fault detection and management system for fault tolerant switched reluctance motor drives," in Conf. Rec. IEEE-IAS Аnnu. Meeting, Sept. 1989, pp. 574-578.

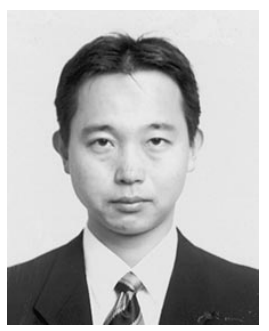

Tadashi Sawata (S'96-A'98) received the B.S. and M.S. degrees from Nagaoka University of Technology, Niigata, Japan, in 1990 and 1992, respectively, and the Ph.D. degree from the SPEED Laboratory, Department of Electronics and Electrical Engineering, University of Glasgow, Glasgow, U.K., in 1998.

In 1992, he joined NSK Ltd., Tokyo, Japan. $\mathrm{He}$ is currently with the Precision Machinery and Parts Technology Center, NSK Ltd., Gunma, Japan, where his work includes the design and development of the direct-drive VR-type "megatorque motor" to meet increasing demands for semiconductor and LCD manufacturing robots.

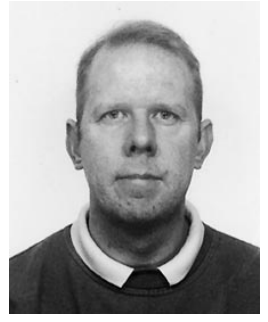

Calum Cossar born in Hamilton, U.K., in 1962. $\mathrm{He}$ received the B.Sc. (Hons.) degree in electronics and electrical engineering from the University of Glasgow, Glasgow, U.K., in 1983.

From 1983 to 1988, he was with Ferranti plc Edinburgh, U.K., where he worked on the design of high-speed digital signal processing for airborne radar applications. In 1988, he joined the SPEED Laboratory, Department of Electronics and Electrical Engineering, University of Glasgow, as a Research Assistant. He became a Research Technologist and has been involved in research and development into the implementation of switched reluctance control.

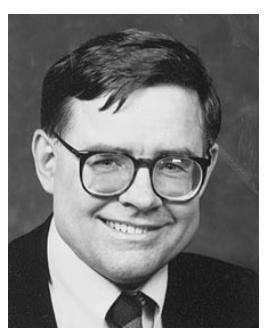

T. J. E. Miller (M'74-SM'82-F'96) is a native of Wigan, U.K. He received the B.Sc. degree from the University of Glasgow, Glasgow, U.K., and the Ph.D. degree from the University of Leeds, Leeds, U.K.

From 1979 to 1986, he was an Electrical Engineer and Program Manager with General Electric Corporate Research and Development, Schenectady, NY. His industrial experience also includes periods with GEC (U.K.), British Gas, International Research and Development, and a student apprenticeship with Tube Investments Ltd. He is currently Lucas Professor in Power Electronics and founder and Director of the SPEED Consortium, Department of Electronics and Electrical Engineering, University of Glasgow, where he is responsible for teaching and research in power electronics and electrical power engineering. The SPEED Laboratory serves some 50 industrial companies in the U.K., U.S., Europe, and Far East with design software for electric motor design, special electronic controls, and development equipment for motor drive systems. He is the author of 105 publications in the fields of motors, drives, power systems, and power electronics, including five books.

Prof. Miller is a Fellow of the Royal Society of Edinburgh and a Fellow of the Institution of Electrical Engineers (U.K.).

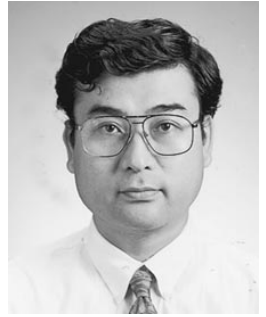

Yoichi Hayashi was born in Gifu, Japan, in 1950 $\mathrm{He}$ received the B.S. and M.S. degrees from Nagoya University, Nagoya, Japan, and the Dr.Eng. degree from Tokyo Institute of Technology, Tokyo, Japan, in 1973, 1975, and 1987, respectively, all in electrical engineering.

From 1975 to 1977, he was a Research Assistan at Ehime University, Matuyama, Japan. From 1977 to 1988 , he was a Research Assistant at Tokyo Institute of Technology. Since 1988, he has been with Aoyama Gakuin University, Tokyo, Japan, as an Associate Professor and a Professor of Power Electronics. From April 1993 to March 1994, he was a Visiting Research Fellow at the SPEED Laboratory, Department of Electronics and Electrical Engineering, University of Glasgow, Glasgow, U.K. He has been engaged in the analysis and control of static converter systems for a variety of applications, including induction motor drives, active power filters, superconducting magnetic energy storage

Prof. Hayashi is a member of the Institute of Electrical Engineers of Japan. systems, and solar-powered vehicles. Catholique de Louvain-la-Neuve, Belgium. From 1993 to 1998, he was a Research Assistan Engineering, University of Glasgow, working with and drives. He is currently a Development Engineer in the Department of
Philip C. Kjaer (S'92-M'93) was born in Montreal,
PQ, Canada, in 1969. He received the M.Sc. degree in electrical engineering from Aalborg University, from the University of Glasgow, Glasgow, U.K., in 1997. His studies included one year at the Universite

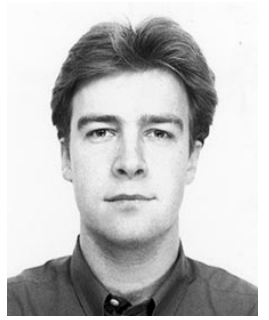

Corporate Research, Västeras, Sweden. His research
ation of electrical machines and power electronic

Crof. Hayashi is a menber of the Insit 